\title{
Congenital Secondary Hypothyroidism Evidences in a Dog
}

\author{
Luana da Silva Meirelles', Maurício Bianchini Moresco ${ }^{2}$, Luciana de Jesus², \\ Guilherme Luiz Carvalho de Carvalho ${ }^{3}$, Márcio Poletto Ferreira ${ }^{4}$ \& Álan Gomes Pöppl ${ }^{4}$
}

\begin{abstract}
Background: Deficiency of thyroid hormones thyroxine (T4) and triiodothyronine (T3) results in multisystemic disease described as hypothyroidism (HpoT). Secondary HpoT is defined by TSH decreased production and, therefore, thyroid hormones. This condition is rare in dogs, accounting for less than $5 \%$ of cases. The objective of this report is to describe evidence of congenital secondary hypothyroidism in a mongrel dog and therapeutic response obtained.

Case: A 3-year-old neutered male mongrel dog was brought to the veterinarian with a history of overweight without polyphagia, associated with discrete alopecia, poor quality skin and hair coat, lethargy and evident exercise intolerance. Physical examination revealed a body condition score of seven (1 to 9 scale), disqueratosis, pyoderma, ventral cervical alopecia, hair thinning on the posterior surface of the pelvic limbs and nonpalpable thyroid. A body conformation characterized by disproportionate dwarfism was observed. Owners provided a former patient's X-ray (18 months of age), showing growth plate non-closure in vertebral bodies. Results of a complete blood count (CBC) and serum biochemical profile were within normal limits except for elevated fructosamine $(459 \mu \mathrm{mol} / \mathrm{L}$; reference range: $170-338 \mu \mathrm{mol} / \mathrm{L})$ and total cholesterol $(558 \mathrm{mg} / \mathrm{dL}$; reference range: $135-270 \mathrm{mg} / \mathrm{dL})$. Analyses of the hormone profile showed decreased levels of canine thyroid-stimulating hormone (cTSH) $0.03 \mathrm{ng} / \mathrm{mL}$ (reference range: $0.05-0.5 \mathrm{ng} / \mathrm{mL}$ ), free thyroxine by equilibrium dialysis (fdT4) $0.57 \mathrm{ng} / \mathrm{dL}$ (reference range: $0.8-3.0 \mathrm{ng} / \mathrm{dL}$ ), and total thyroxine (tT4) $5.1 \mathrm{ng} / \mathrm{mL}$ (reference range: $15-30 \mathrm{ng} / \mathrm{mL}$ ). A distal forelimb X-ray was performed and showed opened epiphyseal growth plates from radius and ulnar bones. The patient was discharged with sodium levothyroxine $(20 \mu \mathrm{g} / \mathrm{kg} \mathrm{PO} \mathrm{q} 24 \mathrm{hr})$ until re-evaluation. The patient was re-evaluated 2 months later and clinical symptoms observed at the first admission were still persistent. CBC and serum biochemical profile were within normal range. The values of T4t and cTSH were $21.3 \mathrm{ng} / \mathrm{mL}$ (reference range for treated dogs $25-45 \mathrm{ng} / \mathrm{mL}$ post-thyroxine) and $0.03 \mathrm{ng} / \mathrm{mL}$ respectively. Owners were administering a generic levothyroxine, and then a commercial sodium levothyroxine was prescribed at the same dose for treatment. Clinical improvement was reported by the owner 4 weeks later. A new forelimb and vertebral radiographic examination performed 6 months later revealed complete epiphyseal ossification.

Discussion: The patient was diagnosed with central hypothyroidism based on the clinical presentation in conjunction with the laboratory tests results. The main hypothesis argues for a congenital pituitary malformation, leading to a defective hypothalamic-pituitary-thyroid axis function. This decreased hormonal TSH secretion culminated in a chronic mild state of hypothyroidism associated with reduction in the thyroid hormones secretion. Metabolic consequences of mild hypothyroidism affect bone development directly and lead to delayed epiphyseal ossification and epiphyseal growth, reduced long bone growth, and disproportionate dwarfism. Studies have suggested a genetic relation with the development of congenital hypothyroidism, although no disease-causing mutations were found in the genes previously investigated. The prognosis for dogs with secondary hypothyroidism due to malformation or destruction of the pituitary ranges from poor to reserved, with shorter life expectancy in dogs with congenital pituitary malformation due to cysts expansion. Although cost is limiting for some owners, advanced imaging such as computed tomography or magnetic resonance may be useful in the macroscopic evaluation of the pituitary gland and are recommended in central hypothyroidism cases.
\end{abstract}

Keywords: disproportionate dwarfism, TSH deficiency, central hypothyroidism, epiphyseal growth.

${ }^{1}$ M.V. Autônoma, Porto Alegre, RS, Brazil. ${ }^{2}$ Graduação, Faculdade de Medicina Veterinária (FaVet), Universidade Federal do Rio Grande do Sul (UFRGS), Porto Alegre. ${ }^{3}$ Mestrando, Programa de Ciências Veterinárias (PPGCV), UFRGS, Porto Alegre. ${ }^{4}$ Departamento de Medicina Animal, FaVet, UFRGS, Porto Alegre. CORRESPONDENCE: A.G. Pöppl [alan.poppl@ ufrgs.br - Tel.: +55 (51) 3308-7856]. Departamento de Medicina Animal, Faculdade de Veterinária, UFRGS. Av. Bento Gonçalves n. 9090. Bairro Agronomia. CEP 91540-460, Porto Alegre, RS, Brazil. 


\section{INTRODUCTION}

Hypothyroidism (HpoT) is a multisystemic disease [10] that results from deficiency of thyroid hormones (TH), thyroxine (T4) and triiodothyronine (T3), whose production is influenced by the hypophysis, the hypothalamus and the thyroid itself [1]. HpoT is of primary origin in about $95 \%$ of cases, affecting mainly middle-aged dogs [5]. In a retrospective study, Pöppl et al. [11] describe HpoT as the third most frequent endocrinopathy in an Endocrinology Service, with an average of $8 \pm 3,39$ year-old at diagnosis.

Secondary HpoT is characterized by the decrease in production of thyroid-stimulating hormone (TSH) and, as a result, of TH secretion as well $[5,10]$. Such condition is unusual in dogs, corresponding to less than $5 \%$ of cases, with the acquired condition being more common $[5,10]$. Nonetheless, a congenital form of secondary HpoT was reported in German Shepherd dogs with pituitary dwarfism, associated with the deficiency of other adenohypophyseal hormones [14]. Secondary HpoT cases caused by isolated TSH deficiency are rare conditions, and were reported in a family of Giant Schnauzer dogs [7], in a Boxer dog [8] and in a Portuguese Water dog [6]. Seven Miniature Schnauzers dogs were diagnosed with central congenital HpoT, three of which presented with dwarfism, whereas four of them did not [13]. The main causes for secondary HpoT include congenital malformation, pituitary destruction (tumors, trauma, autoimmune hypophysitis) or even its suppression, normally caused by hormones or drugs such as glucocorticoids [5].
The aim of this study is to report evidence of secondary hypothyroidism most likely of congenital origin in a dog.

\section{CASE}

A 3-year-old neutered male mongrel dog weighing $10 \mathrm{~kg}$ was brought to a Veterinary Teaching Hospital at Universidade Federal do Rio Grande do Sul (UFRGS) in southern Brazil with a history of overweight without polyphagia, associated with alopecia, poor quality skin and unkempt hair coat with evidence of superficial pyoderma and dryness, respectively; lethargy, and evident exercise intolerance. Physical examination revealed a body condition score of seven (1 to 9 scale), disqueratosis, pyoderma, ventral cervical alopecia, hair thinning on the posterior surface of the pelvic limbs, nonpalpable thyroid and body conformation characterized by disproportionate dwarfism, with large head, short and thick neck, large trunk and short limbs (Figure 1A to D). Owners provided a former patient's thoracolumbar X-ray taken when the dog was 18 months old due to a complaint of gait difficulty, in which the non-closure of vertebral bodies growth plates could be observed (Figure 2A).

Due to clinical HpoT suspicion, laboratory exams and hormonal measurement of total thyroxine (tT4) free thyroxine by equilibrium dialysis (fdT4) and cTSH (canine thyroid-stimulating hormone) were requested to confirm diagnosis. Pyoderma was initially treated with cefalexin $^{1}$ (30 mg/kg bid) for 3 weeks, associated with therapeutic baths with $2 \%$ chlorhexidine-based shampoo ${ }^{1}$.

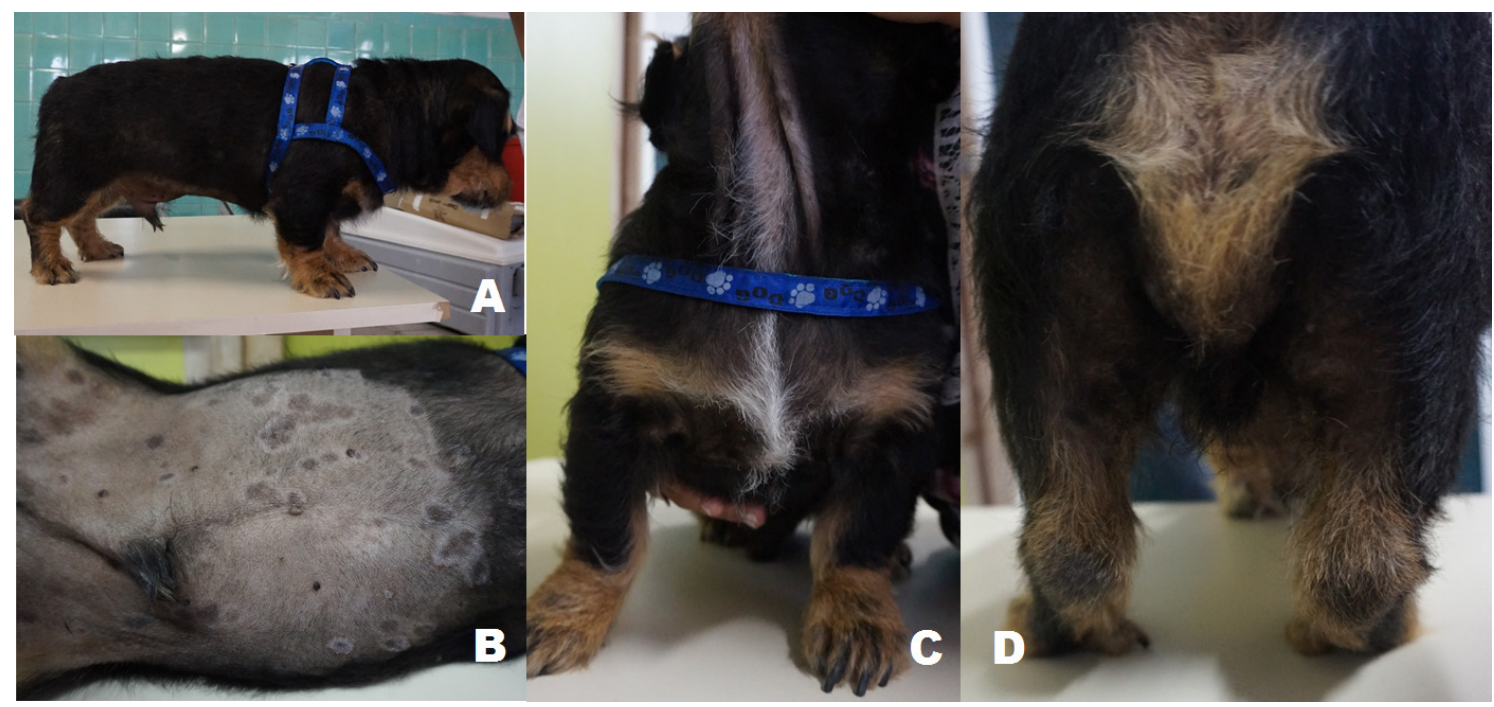

Figure 1. A- Disproportionate dwarfism, short and thick neck, large trunk and short limbs, with hair thinning and dull hair coat; BEpidermal crusts and collarettes secondary to pyoderma, with lesion and skin pigmentation; C- Areas of alopecia and ventral cervical alopecia; D- Areas of alopecia and hypotrichosis in the posterior surface of the pelvic limbs. 


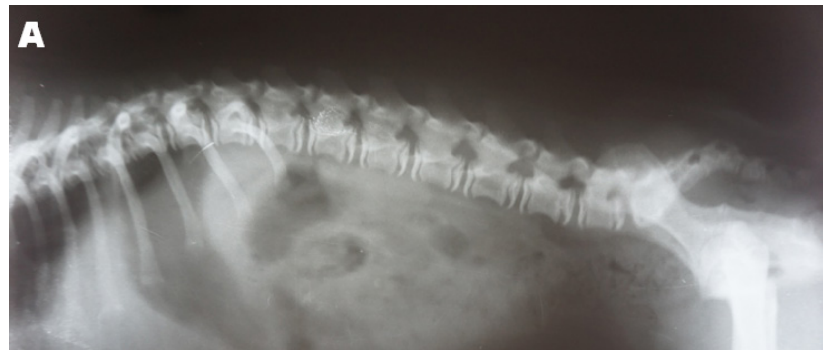

B

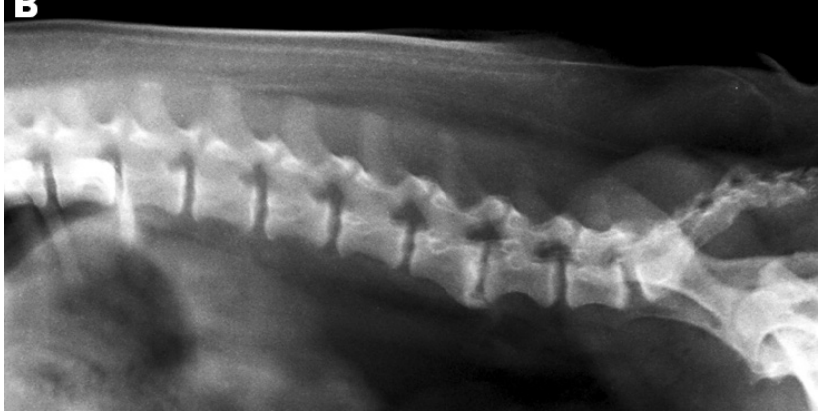

Figure 2. A- Thoracolumbar spine at 18 months of age: non-closure of growth plates in vertebral bodies. B- Thoracolumbar spine at 3 years old after six months of supplementaion with sodium levothyroxine: proper closure of growth plates and articular-surface irregularities in vertebral bodies, associated with ventral spondylosis, more prominent between L5-L6.

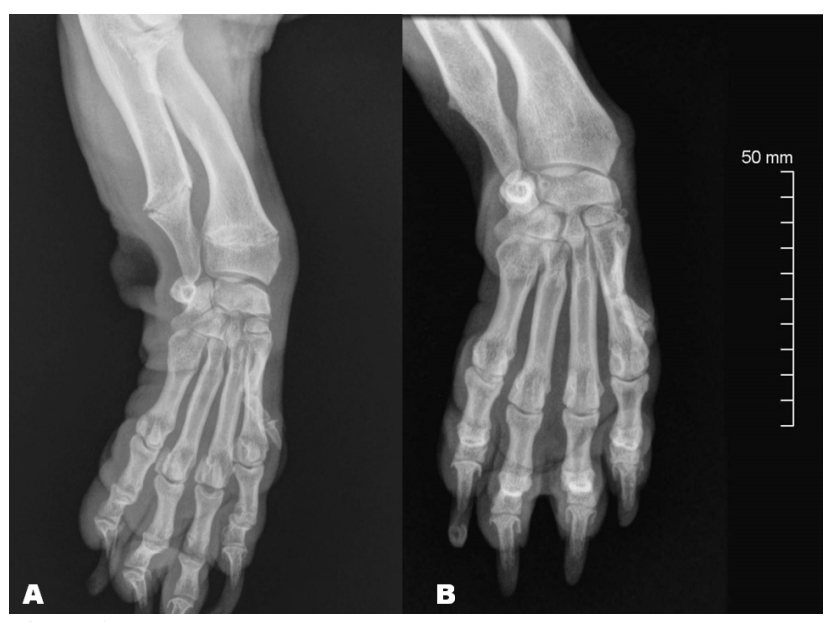

Figure 3. A- Radioulnar $x$-ray of the left forelimb after eight weeks of treatment with generic levothyroxine. Non-closure of epiphyseal plates is observed. B- Radioulnar x-ray after six months of treatment with brandname levothyroxine approved for use in dogs. Complete epiphyseal closure.

The main laboratory findings were erythrogram within reference ranges with erythrocytes (Er) count of 6.09 millions $/ \mathrm{mm}^{3}$ (reference range - RR: 5.5-8.5 millions $/ \mathrm{mm}^{3}$ ), hematocrit (Ht) $43 \%$ (RR: 37-55\%), hemoglobin (Hb) $14.5 \mathrm{~g} / \mathrm{dL}$ (RR: 12-18 g/dL), total cholesterol $558 \mathrm{mg} / \mathrm{dL}$ (RR: $135-270 \mathrm{mg} / \mathrm{dL}$ ), and fructosamine $459 \mu \mathrm{mol} / \mathrm{L}$ (RR: 170-338 $\mu \mathrm{mol} / \mathrm{L}$ ) with $92 \mathrm{mg} /$ dL glycaemia (RR: $65-118 \mathrm{mg} / \mathrm{dL}$ ). Thyroid function assessment showed tT4 $5.1 \mathrm{ng} / \mathrm{mL}$ (RR: $15-30 \mathrm{ng} / \mathrm{mL}$ ), fdT4 $0.57 \mathrm{ng} / \mathrm{dL}$ (RR: 0.8-3.0 ng/dL) and cTSH $0.03 \mathrm{ng} /$ $\mathrm{mL}$ (RR: $0.05-0.5 \mathrm{ng} / \mathrm{mL}$ ), thus suggesting a secondary hypothyroidism diagnosis due to TSH deficiency.
Once HpoT was confirmed, the dog began treatment with sodium levothyroxine ${ }^{2}$ supplementation at the dose of $20 \mu \mathrm{g} / \mathrm{kg}$ orally every $24 \mathrm{~h}$ in fasting state, with a gradual increase in the dose having been prescribed, starting at $5 \mu \mathrm{g} / \mathrm{kg}$, followed by $5 \mu \mathrm{g} / \mathrm{kg}$ increases in the weekly dose until reaching total calculated dose of $20 \mu \mathrm{g} / \mathrm{kg}$ at the end of the fourth week of treatment. At a return appointment in two months after treatment beginning, patient presented with pyoderma resolution, although clinical signs of overweight without polyphagia, alopecia, low quality of hair coat and skin flaking, lethargy and evident exercise intolerance were still evident. A new set of laboratory tests showed an increase in the number of $\operatorname{Er}\left(7.45\right.$ millions $\left./ \mathrm{mm}^{3}\right)$, $\mathrm{Ht}(55 \%)$ and $\mathrm{Hb}$ (17.5 g/dL), cholesterol and fructosamine levels within reference range for the species, in the values of $157 \mathrm{~g} / \mathrm{dL}$ and $191.8 \mu \mathrm{mol} / \mathrm{L}$, respectively. A distal radioulnar $\mathrm{x}$-ray was requested to evaluate the closure of epiphyses (Figure 3A), which revealed non-closure of such structures despite the patient's age of three years old. The values of tT4 after thyroxine and cTSH were $21.3 \mathrm{ng} / \mathrm{mL}$ (target range during therapy: $25-45 \mathrm{ng} / \mathrm{mL}$ ) and $0.03 \mathrm{ng} / \mathrm{mL}$, respectively. When evaluating the administration of the drug with the owner, it was evidenced that the owner was using generic levothyroxine. A recommendation for change in the medication was made, switching to a brand-name levothyroxine approved for use in dogs (Synthroid) ${ }^{3}$ at the dose of $22 \mu \mathrm{g} / \mathrm{kg}$ every $24 \mathrm{~h}$ in fasting state.

After four weeks into therapy with the new medication, owner reported improvement in the dog's level of activity and overall disposition, as well as meaningful change in hair coat quality (Figure $4 \mathrm{~A}$ to D). Total T4 value after thyroxine was $45.7 \mathrm{ng} / \mathrm{mL}$ (target range during therapy: $25-45 \mathrm{ng} / \mathrm{mL}$ ). Due to patient's weight loss $(9 \mathrm{~kg})$, with body condition score reduction to five (1 to 9 scale), the dose of synthetic thyroxine was adjusted to $17 \mu \mathrm{g} / \mathrm{kg}$ every $24 \mathrm{~h}$, in fasting state.

Six months after the beginning of therapy with brand-name thyroxine, the patient underwent another clinical evaluation. Despite a good clinical control of hypothyroidism, the weight had gone up to $9.5 \mathrm{~kg}$. Total T4 value after thyroxine $11 \mathrm{ng} / \mathrm{mL}$ was considered low, associated again with a $0.03 \mathrm{ng} / \mathrm{mL}$ cTSH concentration, therefore a new dose adjustment was made to 19 $\mu \mathrm{g} / \mathrm{kg}$. New distal forelimb and thoracolumbar spine $\mathrm{X}$-rays were performed, revealing complete closure of the radio and ulnar bone epiphyses, and vertebral 


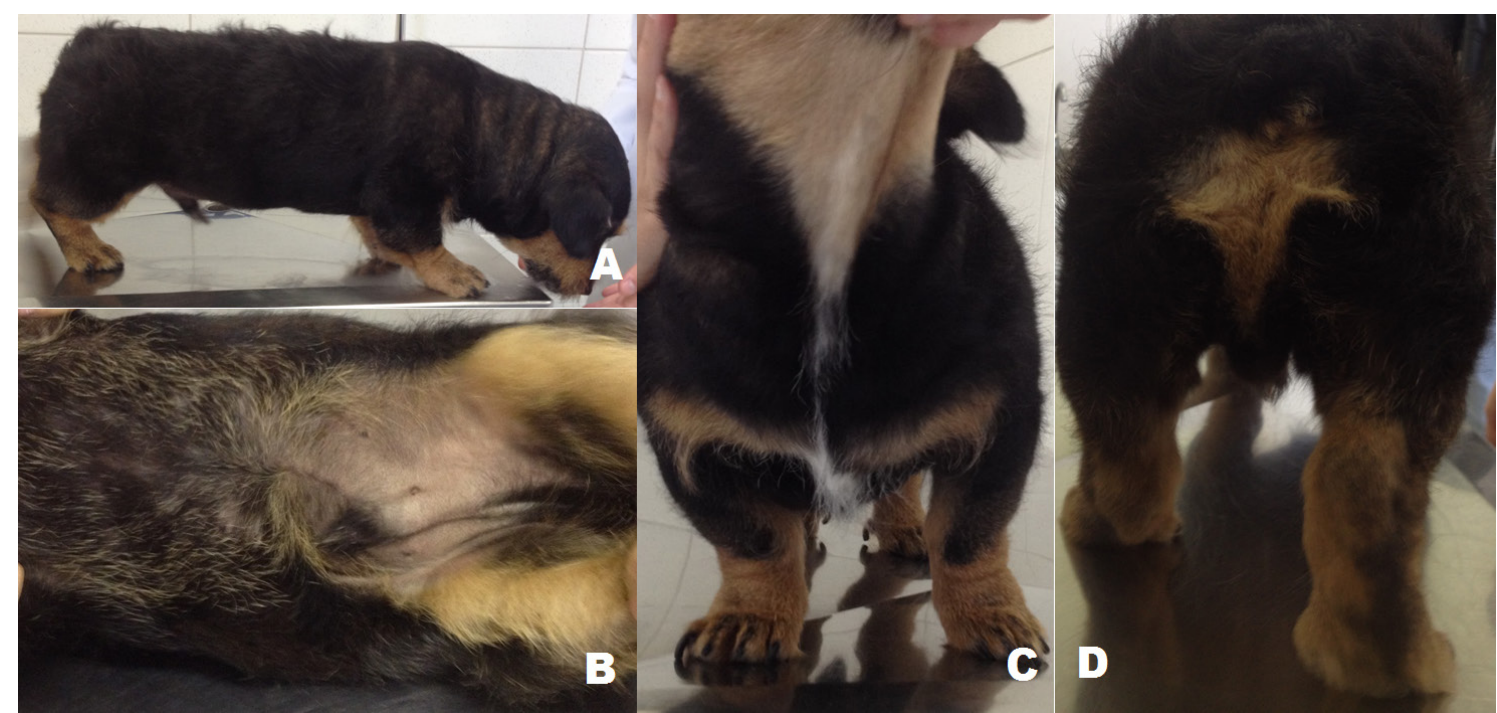

Figure 4. A- Excelent hair coat quality recovery, disproportionate dwarfism body conformation sustained; B- Complete hair coat coverage of ventral abdomen, remission of skin pigmentation and recovery from pyoderma lesions; C- Total hair coat coverage of ventral cervical region; D- Total hair coat coverage of posterior surface of the pelvic limbs.

bodies growth plates closure (Figures $2 \mathrm{~B}$ and $3 \mathrm{~B}$ ). Nevertheless, the spine $\mathrm{X}$-ray demonstrated irregularities in terminal lamina surfaces of vertebral bodies, with ventral spondylosis formation, more prominent between L5-L6 (Figure 2B).

\section{DISCUSSION}

In the present report, clinical signs, laboratory findings and diagnostic hormone assay for central HpoT are observed [2,3,9]. Evidences in the present case point towards congenital pituitary malformation, leading to partial dysfunction in hypothalamic-pituitary-thyroid axis, resulting in decrease of TSH production, with consequent reduction in $\mathrm{TH}$ production.

TH acts in synergy with growth hormone (GH) and insulin-like growth factor-1 (IGF-1) in the promotion of chondrogenesis $[4,12]$. Delayed closure of bone epiphysis, retarded epiphyseal growth, and long bones growth reduction cause disproportionate dwarfism in cases of congenital HpoT; or HpoT acquired during bone development $[5,10,12]$. In congenital cases, growth deficit is not evident at birth, but becomes noticeable after two to twelve weeks $[5,13]$. In such cases, signs of HpoT are present since the first year of life, as is the case here reported, a condition observed in just $1 \%$ of hypothyroid patients [11]. The non-closure of growth plates evidenced in the present case points towards early onset hypothyroidism, with the low TSH serum concentration being a marker for secondary HpoT $[1,5,10]$. It is likely that despite proper closure of patient's growth plates after adequate thyroxine supplementation, the irregularities in the articular surfaces of vertebral bodies and spondylosis are deformities developed because of lack of TH during patient's development $[3,12,13]$.

It is believed that the pituitary dwarfism already described in German shepherd dogs and Schnauzers has a genetic component, caused by an autosomal recessive mutation $[7,13,14]$. However, no diseasecausing mutations were observed in the genes investigated up to this moment. In a retrospective study in Miniature Schnauzers dogs with central HpoT it was possible to observe two distinct subclasses of disease clinical presentation. They may, or may not culminate in disproportionate dwarfism. Moreover, different age presentations were reported, suggesting a probable mild or severe deficiency in TSH secretion in association with the different clinical manifestations of this condition. Nonetheless, those different presentations do not rule out central HpoT of congenital origin when disproportionate dwarfism is not reported [13]. Canine TSH assays has an average $80 \%$ sensitivity $[5,9]$. The fact that the patient in this case report presents low TSH concentrations, however still detectable in the canine TSH assay used, is consistent with mild deficiency, thus justifying lack of more serious malformations. Patients with primary HpoT may eventually initiate the process of lymphocytic-plasmocytic thyroiditis with less than one year of age, presenting bone development deficiencies like those described in congenital cases. Primary cases, however, show elevated TSH levels, unlike what 
was observed in the reported case, even when thyroxine supplementation was considered insufficient [9].

The treatment of choice, regardless of origin, is the administration of synthetic sodium levothyroxine approved for use in dogs in its available forms [5,10]. Despite the improvement in hematological and biochemical parameters associated to HpoT like hypercholesterolemia and hyperfructosaminemia with generic levothyroxine use, serum concentration of tT4 only reached the target range, accompanied by improvement in clinical signs, when a commercial product approved for use in dogs was administered. This observation agrees with the need to adopt medicine forms whose use has been approved for dogs when treating HpoT.

Prognosis for dogs with secondary HpoT due to malformation or destruction of the pituitary gland varies from poor to reserved, with shorter life expectancy for dogs with congenital malformation of the pituitary due to eventual expansion of cysts associated with the malformation. Advanced imaging exams such as computed tomography or magnetic resonance are useful in macroscopic evaluation of the pituitary gland [5], but could not be performed in this case since the owner did not consent to it. Likewise, an ultrasound exam of the thyroid gland would be important for the evaluation of thyroid parenchyma [5] even though the presence/absence of goiter had not been evidenced at physical examination. The information gathered in the present case, however, evidences a rare manifestation of congenital secondary hypothyroidism.

\section{MANUFACTURERS}

${ }^{1}$ Virbac do Brasil Indústria e Comércio Ltda. Jurubatuba, SP, Brazil. ${ }^{2}$ Merck Sharp \& Dohme Ltda. São Paulo, SP, Brazil.

${ }^{3}$ Abbott Laboratórios do Brasil. Rio de Janeiro, RJ, Brazil.

Declaration of interest. The authors report no conflicts of interest. The authors alone are responsible for the content and writing of the paper.

\section{REFERENCES}

1 Cooper D.S. \& Ladenson P.W. 2013. Glândula Tireoide. In: Gardiner D.G. \& Shoback D. (Eds). Endocrinologia básica e clínica de Greenspan. 9th edn. New York: McGraw Hill, pp.163-214.

2 Credille K.M., Slater M.R., Moriello K.A., Nachreiner R.F., Tucker K.A. \& Dunstan R.W. 2001. The effects of thyroid hormones on the skin of Beagle dogs. Journal of Veterinary Internal Medicine. 15: 539-546.

3 Dixon R.M, Reid S.W.J \& Mooney C.T. 1999. Epidemiological, clinical, haematological and biochemical characteristics of canine hypothyroidism. The Veterinary Record. 145: 481-487.

4 Engelking L.R. 2006. Tireoide: II Efeitos metabólicos dos hormônios tireoidianos. In: Fisiologia endócrina e metabólica em medicina veterinária. 2.ed. São Paulo: Roca, pp.104-105.

5 Feldman E.C. \& Nelson R.W. 2015. Hypotyroidism. In: Canine and feline endocrinology and reproduction. 4th edn. St. Louis: Elsevier, pp.77-135.

6 Gal A., Raetzman L.T., \& Singh K. 2012. Congenital adenohypophyseal hypoplasia associated with secondary hypothyroidism in a 2-week-old Portuguese water dog. The Canadian Veterinary Journal. 53: 659-664.

7 Greco D.S., Feldman E.C., Peterson M.E., Turner J.L., Hodges C.M. \& Shipman L.W. 1991. Congenital hypothyroidism in a Family of giant schnauzers. Journal of Veterinary Internal Medicine. 5(2): 57-65.

8 Mooney C.T. \& Anderson T.J. 1993. Congenital hypothyroidism in a Boxer dog. Journal of Small Animal Practice. 34: 31-35. 9 Panciera D.L. 1999. Is it possible to diagnose hypothyroidism? Journal of Small Animal Practice. 40: 152-157.

10 Panciera D.L., Peterson M.E. \& Bichard S.J. 2000. Diseases of the thyroid gland. In: Bichard S.J. \& Sherding R.G. (Eds). Saunder's manual of small animal practice. 2nd edn. Philadelphia: W.B. Saunders, pp.235-242.

11 Pöppl A.G., Coelho I.C., Silveira C.A., Moresco M.B. \& Carvalho G.L.C. 2016. Frequency of endocrinopathies of affected dogs and cats assessed by a division of veterinary endocrinology in southern Brazil: 1400 cases (2004-2014). Acta Scientiae Veterinariae. 44: 1379.

12 Saunders H.M. \& Jezyk P.K. 1991. The radiographic appearance of canine congenital hypothyroidism: skeletal changes with delayed treatment. Veterinary Radiology \& Ultrasound. 32(4): 171-177.

13 Voorbij A.M., Leegwater P.A., Buijtels J.J., Daminet S. \& Kooistra H.S. 2016. Central hypothyroidism in Miniature Schnauzers. Journal of Veterinary Internal Medicine. 30: 85-91.

14 Voorbij A.M., van Steenbeek F.G., Vos-Loohuis M., Martens E.E., Hanson-Nilsson J.M., van Oost B.A., Kooistra H.S. \& Leegwater P.A. 2011. A contracted DNA repeat in LHX3 intron 5 is associated with aberrant splicing and pituitary dwarfism in German shepherd dogs. PLoS One. 6(11): e27940.

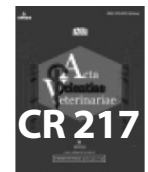

